Revue bibliographique pour le domaine irano-aryen

\title{
Violla Allegranzi. « Vers un réexamen des inscriptions historiques du monde iranien pré- mongol : Étude des cas des mausolées de Tim et de Termez en Ouzbékistan »
}

\section{Sandra Aube}

\section{OpenEdition}

\section{Journals}

Édition électronique

URL : https://journals.openedition.org/abstractairanica/53969

DOI : 10.4000/abstractairanica.53969

ISSN : 1961-960X

Éditeur :

CNRS (UMR 7528 Mondes iraniens et indiens), Éditions de l'IFRI

Référence électronique

Sandra Aube, "Violla Allegranzi. « Vers un réexamen des inscriptions historiques du monde iranien pré-mongol : Étude des cas des mausolées de Tim et de Termez en Ouzbékistan » », Abstracta Iranica [En ligne], Volume 42-43 | 2021, document 16, mis en ligne le 30 décembre 2021, consulté le 29 décembre 2022. URL : http://journals.openedition.org/abstractairanica/53969; DOI : https://doi.org/ 10.4000/abstractairanica.53969

Ce document a été généré automatiquement le 29 décembre 2022.

Tous droits réservés 


\title{
Violla Allegranzi. « Vers un réexamen des inscriptions historiques du monde iranien pré- mongol : Étude des cas des mausolées de Tim et de Termez en Ouzbékistan »
}

\author{
Sandra Aube
}

\section{RÉFÉRENCE}

Violla Allegranzi. «Vers un réexamen des inscriptions historiques du monde iranien pré-mongol : Étude des cas des mausolées de Tim et de Termez en Ouzbékistan » in Viola Allegranzi, Valentina Laviola (eds.). Texts and Contexts. Ongoing Researches on the Eastern Iranian World (Ninth-Fifteenth c.). Rome: Istituto per l'Oriente C.A. Nallino (Pubblicazioni dell'Istituto per l'Oriente C.A. Nallino, nr. 120), 2020, p. 103-134

1 Spécialiste de l'épigraphie monumentale persane des premiers siècles de l'Islam (voir la publication de sa thèse, Aux sources de la poésie ghaznavide. Les inscriptions persanes de Ghazni (Afghanistan, XIe-XIIe s.), Paris: Presses Sorbonne Nouvelle, 2019 (cf. le compte rendu dans ce même numéro d'AbstIr), Viola Allegranzi propose ici une étude rigoureuse, précise et très documentée de deux inscriptions historiques aussi célèbres qu'importantes pour l'histoire culturelle et architecturale du monde iranien aux IX ${ }^{\mathrm{e}}$ XII siècles.

2 L'auteur réévalue tout d'abord l'inscription royale samanide qui encadre le portail du mausolée dit Arab-Ata à Tim (p.105-112). Elle analyse, contextualise et complète la lecture de cette inscription arabe, et en propose une nouvelle transcription et une 
traduction originale en français. Allegranzi s'attache également à étudier le style graphique novateur de cette inscription: un aspect particulièrement important puisqu'il s'agit ici de l'une des plus anciennes inscriptions monumentales datées à avoir une graphie agrémentée de rinceaux et d'ornements végétaux (style "coufique fleuri»). Le réexamen de cette inscription par Allegranzi est une contribution importante, et ce d'autant plus que la nature du texte conservé est un témoignage historique exceptionnel: le texte est daté et il s'agit de l'unique inscription monumentale conservée d'un émir samanide, Nūḥ II b. Manșūr (r. 976-997), qu'Allegranzi identifie comme étant le commanditaire - et non le dédicataire - d'un mausolée, peut-être destiné à son père Manșūr I ${ }^{\mathrm{er}}$.

Dans la seconde partie de son article, Allegranzi s'intéresse au texte de fondation du mausolée d'al-Ḥakīm al-Tirmidī (m. 198/910 ?) à Termez (p. 112-123). L'auteure met en avant l'absence d'interactions entre chercheurs russophones et anglophones, et leurs conséquences sur l'interprétation de cette inscription. Ce texte, qui commémore probablement une rénovation du mausolée et de son décor, avait été rapproché du souverain qarākhānide Ahmad $\mathrm{b}$. Hịdr, pour lequel les dates de règne étaient l'objet de dissensions (daté de 473-488/1081-1095 par Masson, de 473-482/1082-1089 par Blair). La prise en compte des sources numismatiques permet tout d'abord à Allegranzi de rétablir un règne en deux phases: de 1086 à 1089 puis de 1092 à 1095. Mais l'auteure rappelle également que les attributions des chercheurs russes ont plutôt associé cette inscription au gouverneur Aḥmad b. Abū Bakr b. Qumāč (actif sous le règne de Sanğar, 511-552/1118-1157). Cette interprétation induit une datation beaucoup plus tardive, avec la mise en place d'un premier programme décoratif au XI ${ }^{e}-\mathrm{XII}^{\mathrm{e}}$ siècle, suivi d'une phase de rénovation entreprise dans le second quart du XII ${ }^{\mathrm{e}}$ siècle - que commémore par la présente inscription. Le hiatus avec chercheurs russes et occidentaux est patent. Allegranzi propose une nouvelle lecture de cette inscription, accompagnée d'une nouvelle transcription, qu'elle prend soin de comparer aux lectures antérieures du texte (qu'elle retranscrit également). Elle offre ainsi un appareil critique étayé, qui la conduit à mettre en exergue les surinterprétations qui ont pu être faites à partir des données de l'inscription. Son analyse de la longue chaîne des titres honorifiques déployés, notamment, démontre un déploiement de titres en arabe, turc et persan, retentissants mais contradictoires, qui font de cette inscription un cas unique dans le monde iranien pré-mongol. Allegranzi en conclue que si leur analyse atteste d'une " volonté du commanditaire de légitimer son pouvoir en se rattachant aux différentes traditions culturelles en interaction dans le monde iranien des XI $-\mathrm{XII}^{\mathrm{e}}$ siècles » (p. 120), elle ne permet finalement pas de faire la lumière sur l'identité du commanditaire.

4 En remettant en cause deux attributions pourtant communément admises et répétées à tort depuis des décennies, Allegranzi illustre brillamment ce que l'approche épigraphique peut apporter à l'histoire du monde iranien oriental. L'impact de cette étude doit être d'autant plus conséquente que les deux monuments en question sont emblématiques des études en architecture islamique, et que les inscriptions monumentales attestant d'un mécénat royal aux IX'-XII ${ }^{e}$ siècles sont rares. 


\section{AUTEURS}

SANDRA AUBE

CNRS, CeRMI, Paris 